\title{
Aquilo que se vê através da arte se vê melhor!
}

\author{
Paula Rodrigues (UDESC)
}

\begin{abstract}
RESUMO: O presente artigo buscou apresentar a produção teórico-prática realizada durante a disciplina "Sobre Ser Artista Professor", ministrada pela professora Dra. Jociele Lampert, cursada pela aluna Dt. Paula Rodrigues durante o segundo semestre de 2018 no Programa de Pós-Graduação em Artes Visuais no Centro de Artes da UDESC. No tocante a análise a respeito da produção da discente pretendeu-se, primeiramente, apresentar a disciplina e, posteriormente, os trabalhos desenvolvidos dando ênfase na experimentação, no processo criativo e nos conhecimentos apreendidos, bem como no resultado final do trabalho e na reflexão proporcionada por eles.
\end{abstract}

PALAVRAS-CHAVE: artista. Professor. Arte. Processo e experimentação.

ABSTRACT: The present article sought to present the theoretical-practical production carried out during the course "About Being an Artist Professor", taught by the teacher Phd. Jociele Lampert, studied by the student Dt. Paula Rodrigues during the second half of 2018 in the Postgraduate Program in Visual Arts at the UDESC Arts Center. With regard to the analysis of the student's production, it was first intended to present the discipline and, subsequently, the work developed with emphasis on experimentation, the creative process and the knowledge learned, as well as the final result of the work and the reflection provided for them.

KEYWORDS: artist. Teacher. Art. Process and experimentation.

O presente texto busca apresentar a produção realizada durante a disciplina "Sobre Ser Artista Professor", ministrada pela professora dra Jociele Lampert, cursada pela aluna Paula Rodrigues durante o segundo semestre de 2018 no Programa de Pós-Graduação em Artes Visuais no Centro de Artes da UDESC.

$\mathrm{Na}$ perspectiva da análise a respeito da produção da aluna pretende-se apresentar a disciplina e, posteriormente, os trabalhos desenvolvidos dando ênfase na experimentação, no processo criativo e nos conhecimentos apreendidos, bem como no resultado final do trabalho e na reflexão proporcionada por eles.

A disciplina "Sobre ser artista professor" tem, como objetivo, em sua ementa pontuar as referências, métodos e 
ferramentas de ensino e aprendizagem sobre ser professor/artista/pesquisador no contexto escolar. Evidenciando a relação entre o estúdio de arte e a arte educação. Cartografias como forma de ensino e aprendizagem. A metodologia acontece por meio de aulas expositivas e dialogadas sobre os textos estudados e através da realização de exercícios práticos no ateliê de pintura.

A partir da ementa foi possível identificar que a mesma estava dividida em seis momentos. O primeiro momento era o introdutório a disciplina e a temática, acolhendo o autor John Dewey e suas considerações a respeito da arte como experiência. O segundo momento contou com uma aula aberta intitulada: "Pensamento reflexivo e trabalho docente" e com o minicurso: "Comunicação como arte" e " O professor como artista" ministrados pelo professor Dr. Marcus Vinícius e pela Dra. Tatiane da Silva. O terceiro momento trouxe uma aula prática com experimentações em sala de aula. O quarto momento contou com a aula aberta e um mini curso abordando os seguintes assuntos: "Arte e experiência estética: produção, recepção e significação", "Arte e verdade", "Martin Heidegger e Eduardo Chillida", "Arte e Significação", "Hans-Georg Gadamer: a experiência estética e o mundo" e "Arte e Compreensão" com o professor Dr. José Carlos Pereira. O quinto momento trouxe outras aulas práticas e o sexto momento contou com a apresentação de seminários por parte dos alunos a respeito das vivências e relações estabelecidas durante todo o semestre com o conteúdo apresentado pela professora, pelos palestrantes, pelos textos trabalhados e pelos exercícios realizados.

\section{Redescobrindo John Dewey}

Em 2011 iniciei meu mestrado em Design na Universidade Anhembi Morumbi. Dentre os muitos presentes que esse período 
de estudos me proporcionou, com certeza ter conhecido a professora Ana Mae Barbosa foi um dos melhores. Recordo-me como se fosse hoje suas falas apaixonadas sobre arte-educação e toda a luta travada por ela e demais estudiosos para que o estudo da arte-educação ganhasse espaço no Brasil bem como reconhecimento.

Foi durante suas aulas que fui apresentada a John Dewey. Foi uma apresentação breve, mas que me deixou feliz, pois me identificava com o pensamento de Dewey. Em seu discurso Ana Mae pontuava como o autor havia sido incompreendido por muito tempo e recentemente estava sendo resgatado por pesquisadores e estudiosos da área.

Guardei suas palavras e continuei meus estudos na minha linha de pesquisa em arte, design e tecnologia. Já em 2018, quando participei da seleção do doutorado fui convidada a recordá-lo, novamente, pelas palavras da profa. Ana Mae através de seu livro Redesenhando o Desenho (o qual tive a honra em participar com um desenho e um relatol e pelas palavras da profa. Jociele e suas considerações a respeito da arte como experiência.

\section{O Pensamento de Dewey}

No segundo momento mais uma vez fui convidada a recordar o pensamento de Dewey tanto na aula aberta, como no minicurso do prof. Marcus Vinícius. Nele lembrei muito do que Ana Mae falava em suas aulas e tive a oportunidade de acompanhar a maneira de Dewey de ver a relação da educação com a arte. Foi um período de grande aprendizagem.

Durante esse processo percebi que me identifico com o pensamento de Dewey e da liberdade que propunha no ensino e na relação que estabelecia entre aluno e professor. Apesar de considerar uma leitura densa e, por vezes, difícil acredito 
ser de grande importância. Através da fala do prof. Marcus Vinícius ficou explícita a contribuição de Dewey ao ensino da arte no Brasil e ao ensino da arte no âmbito da educação de crianças. Identificando como os professores compreendem os conceitos de arte educação e o modo como os articulam para constituírem métodos de ensino.

Dewey conceitua a arte como experiência e foi isso que nos foi permitido vivenciar nas aulas práticas da disciplina, a partir de diversos momentos que articulavam teoria, prática, poesia e arte. Evidenciando não somente um fazer artístico, mas também o pensamento reflexivo daquilo que se propunha, ou seja, o resultado não era tão importante quanto o processo.

\section{Sobre ser artista $\mathbf{x}$ ser professor}

Foi durante esse terceiro momento da disciplina com atividades práticas que envolviam a experimentação, a percepção e o pensamento reflexivo que pude estabelecer diálogos entre o que havia lido nos textos, ao que tinha visto e escutado na aula aberta e no minicurso. Recordo que uma das atividades propunha uma reflexão a respeito da nossa visão mediante a dualidade sobre ser artista $x$ ser professor.

Penso que depois de concluir minhas duas graduações, uma em artes plásticas e a outra em design de moda, segui um caminho que sempre dialogou com o mercado, com a academia e com a produção artística e durante esse percurso os rótulos sempre me incomodaram, como aquela pergunta padrão de qualquer preenchimento de cadastro, qual a sua profissão?

Recordo-me que a dúvida era uma companheira constante a respeito da resposta devia ter, algumas vezes coloquei artista e as pessoas me olharam de forma estranha, outras vezes coloquei professora e recebi um olhar de pena, também coloquei professora universitária e percebi um olhar de respeito e por 


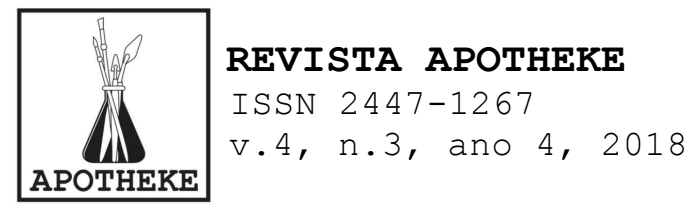

fim designer de moda, esse olhar até hoje foi o mais estranho, pois sentia que as pessoas me olhavam com certo glamour.

A partir dessas vivências, quando fui questionada durante uma atividade da disciplina se me considerava artista ou professora, me vi novamente tentando responder uma pergunta de preenchimento de cadastro que considero irrelevante, não vejo necessidade de separar o artista do professor. E foi a partir desse pensamento que construí o meu painel.

Não acredito que é preciso de tanta "pureza" e "preciosismos" na arte. Sou a favor dos diálogos, das interdisciplinaridades, das transdisciplinaridades, das diversas possibilidades de articulação e diálogo que uma área pode propor a outra, sem necessidade de rótulos, de limites ou amarrações. Vejo todas essas designações de artista, professor, designer, entre outros como parte de um todo que busca experimentações, vivências, processos e aprendizados possíveis e diversificados.

Portanto considero que sou professora, sou artista, sou designer e serei tudo mais que a vida me apresentar e que faça meu coração pulsar com o interesse de algo novo, que possibilite que eu seja melhor e mais apaixonada pelo meu trabalho, sem seguir regras da CAPES ou tradições enrijecidas da academia que limitam e aprisionam. Como afirmou o professor João Carlos às palavras são uma chatice, e complemento, os rótulos então nem se fala.

\section{Experiência Estética}

Dando continuidade ao semestre, a disciplina trouxe no quarto momento a aula aberta e o minicurso do prof. José Carlos, um português simpático de fala pausada que fez meus pensamentos fluírem através de seu discurso. Afinal não é todo dia que você escuta alguém falar sobre arte e experiência 
estética, pontuando a respeito de produção, recepção e significação com tanta propriedade. Além de outros temas como: arte e verdade, arte e significação, experiência estética e o mundo e arte e compreensão, trazendo autores de pesos, muitos dos quais nunca havia estudado como: Martin Heidegger, Eduardo Chillida e Hans-Georg Gadamer.

Posteriormente, após o bombardeio de informações que o prof. José Carlos havia apresentado tivemos algumas aulas teóricas e práticas que versaram sobre outras possibilidades de ver, perceber e sentir o mundo, as coisas ao nosso redor e a própria arte, a partir da leitura de textos e do contato com artistas como John Cage, Allan Kaprow, Beuys, Howard Gardner, Joaquim Jesus, John Dewey, entre outros e as relações que estabeleciam com as práticas artísticas como pesquisa.

\section{Práticas Artísticas como Pesquisa}

No quinto momento algumas atividades foram realizadas, faço abaixo um pequeno relato de cada uma delas, com algumas imagens, para ilustrar um pouco dos processos propostos no tocante à reflexão sobre nossas práticas artísticas enquanto pesquisadores.

A primeira atividade (Fig. 01) foi uma prática que envolvia a escuta e o registro. Cada aluno sentava em frente à mesa que dispunha de papel branco em tamanho A3, três lápis de cores e um limão. A professora então solicitou que cada aluno experimentasse o limão, depois fechasse os olhos e pegasse um dos lápis. Então ela ligou um áudio que tinhas sons aleatórios como crianças rindo, barulhos diversos, entre outros e solicitou que seguindo o que estávamos escutando riscássemos o papel seguindo o ritmo e a intensidade do som. Essa atividade se repetiu algumas vezes e depois foi solicitado que abríssemos os olhos para ver o que tínhamos produzido. Depois 


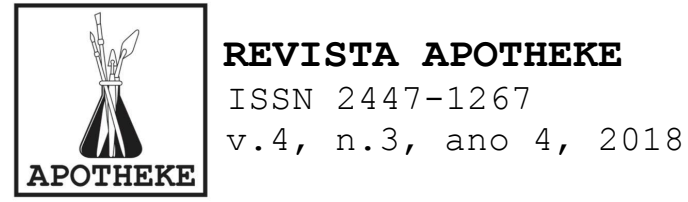

fomos convidados a circular entre as mesas para ver o que nossos colegas haviam feito. Posteriormente, em conjunto conversamos e refletimos sobre a prática realizada.

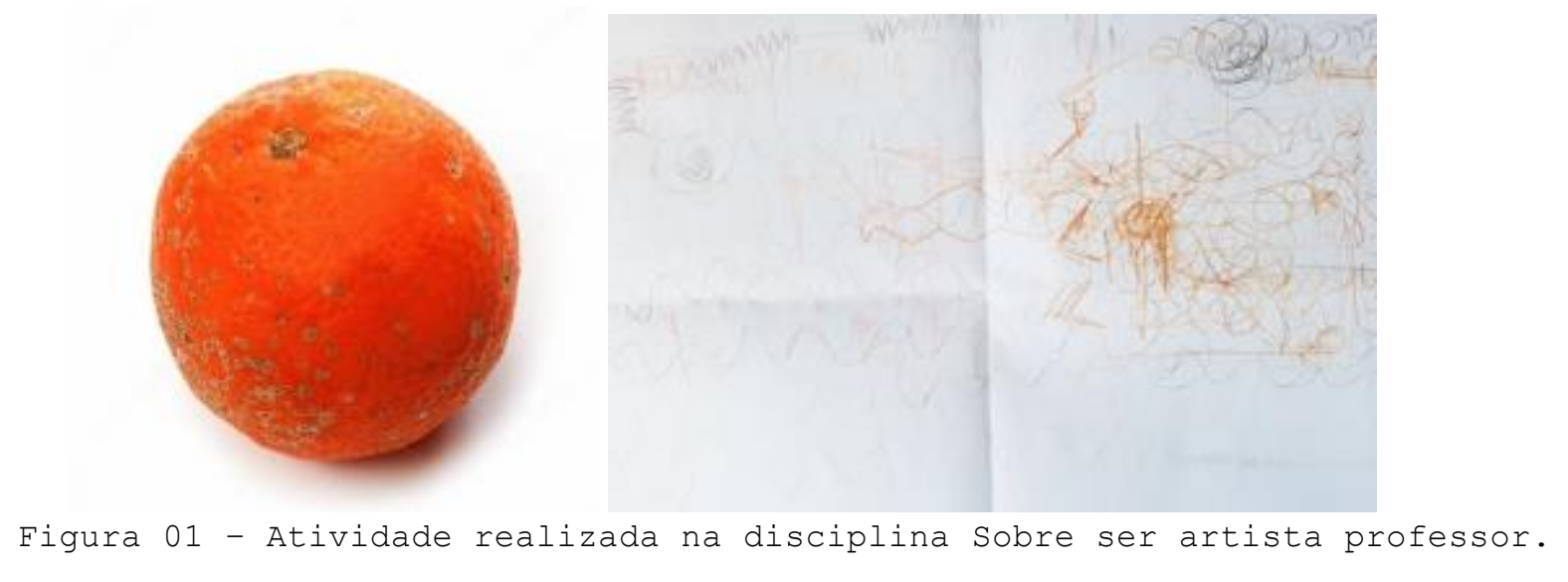
Fonte: Acervo pessoal.

Para a segunda atividade (Fig. 02) nos foi dado uma lupa, um pedaço de um repolho, uma folha grande de papel craft e uma barra de carvão. Nessa atividade, devíamos olhar através da lupa para realizar o desenho do repolho, buscando visualizar todas as suas formas, linhas, volumes, realizando um recorte, de forma que o resultado apresentasse aquilo que cada aluno estava vendo aliado a suas referências, seu estilo e seu traço.
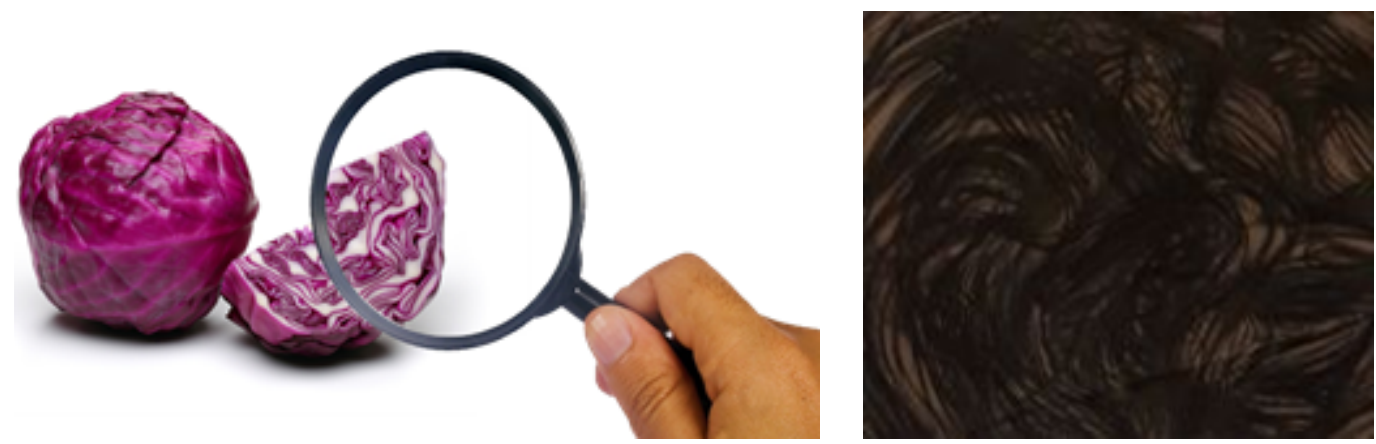

Figura 02 - Atividade realizada na disciplina Sobre ser artista professor. Fonte: Acervo pessoal. 


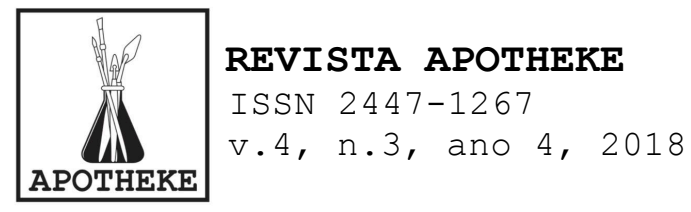

Depois de finalizada a atividade nos foi solicitado recortar o papel de forma a "emoldurá-lo" dando destaque ao que realmente queríamos e depois colar na parede formando um grande mural (Fig. 03). Esse mural foi criado em conjunto por toda a turma, cada aluno interferia como quisesse. Ao final a união de todos os desenhos formou uma obra única a qual passou por uma reflexão dos alunos em conjunto com a professora.
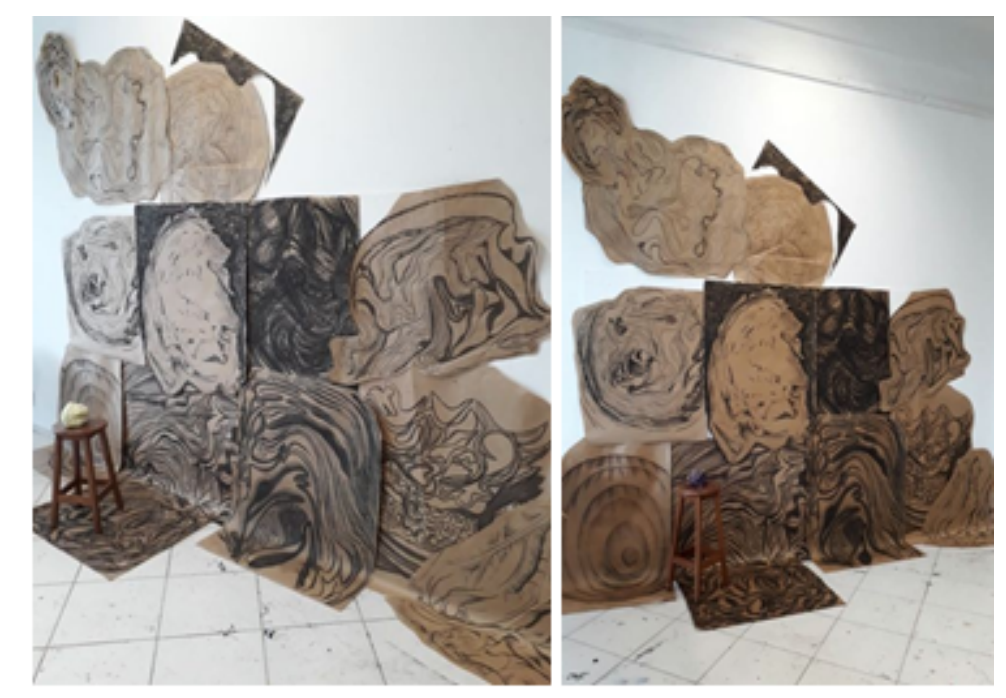

Figura 03 - Atividade realizada na disciplina Sobre ser artista professor. Fonte: Acervo pessoal.

$\mathrm{Na}$ terceira atividade trabalhamos o transfer de imagem a laser. Nessa prática nos foi solicitado levar imagens referentes à nossa pesquisa com impressão a laser para serem transferidas para o canvas, uma espécie de tecido próprio para tela. No primeiro momento era preciso passar uma camada generosa de medium e depois colocar a impressão com a imagem impressa no sentido da camada de médium, ainda úmida, para depois tirar todas as bolhas de ar com uma espátula. Depois de colada a impressão no canvas era preciso esperar um dia para que tudo secasse e depois com água ir retirando as camadas de papel até a imagem aparecer espelhada. 


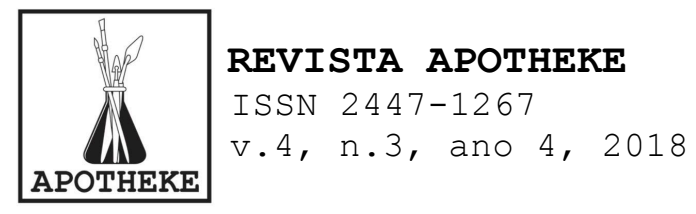

Essa foi uma prática muito interessante, pois requer paciência tanto na espera da secagem do material como na retirada das camadas de papel posteriormente como água, que devia ser bem dosada. Penso que esse processo de "revelação" desse transfer nos permitiu uma reflexão a respeito do trabalho que estava sendo realizado e o tempo que cada processo demanda antes da obra pronta.

No meu caso, depois da obra pronta ainda realizei uma interferência fazendo uso da técnica que estudo em minha pesquisa, ou seja, o bordado (Fig.04). Fiz uma coroa de flores na cabeça da mulher presente em meu trabalho. A ideia de interferir na obra surgiu pelo fato da mesma não ter muitas cores, dessa forma as linhas colorida do bordado deram um pouco de alegria ao trabalho no final e tridimensionalidade.

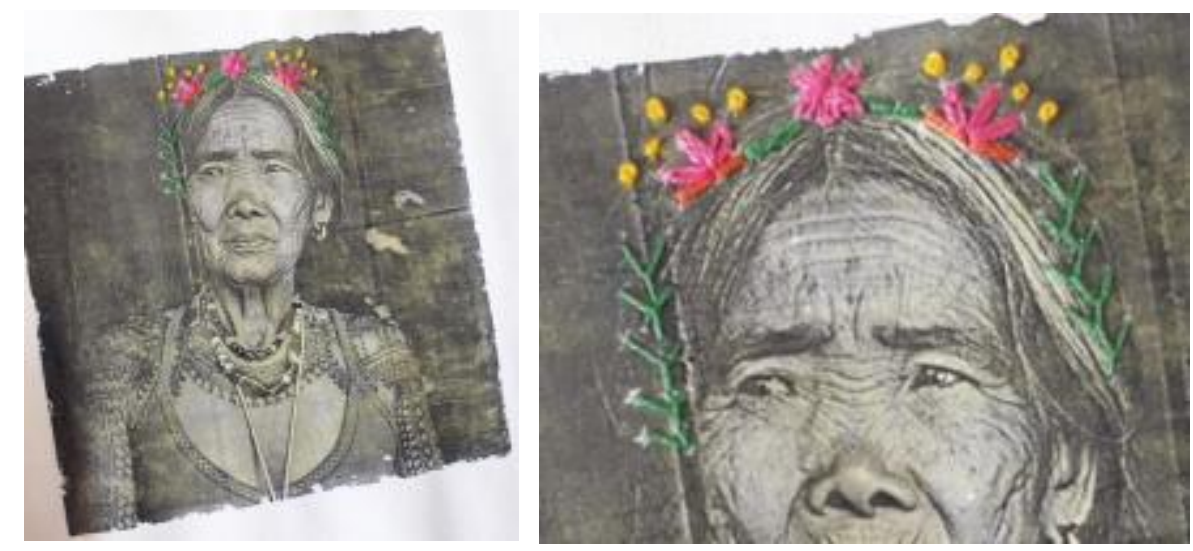

Figura 04 - Atividade realizada na disciplina Sobre ser artista professor. Fonte: Acervo pessoal.

A quarta atividade foi à prática da monotipia, ou seja, a transferência de uma imagem para outra superfície (Fig. 05). Nesse caso fizemos a impressão de outras imagens também referentes à nossa pesquisa em acetato e posteriormente as transferimos para diversos tipos de papel, observando como o suporte poderia interferir no resultado do trabalho. Nos foi permitido fazer interferências com ponta seca, mas optei por 


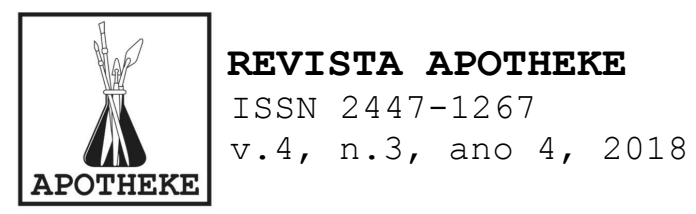

não fazer, pois já tinha intenção de novamente interferir com o bordado.

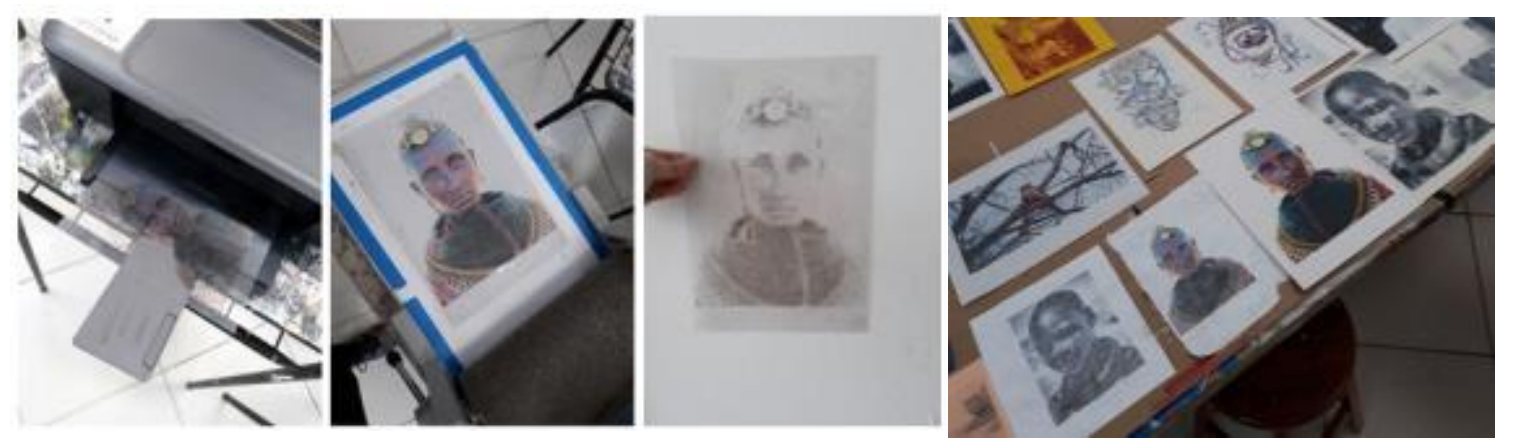

Figura 05 - Atividade realizada na disciplina Sobre ser artista professor. Fonte: Acervo pessoal.

Nessas duas atividades foi possível fazer uma reflexão a respeito de nossa pesquisa, pois fomos provocados em buscar imagens que dialogassem com nossa temática e com os estudos que estamos realizando e foi além ao nos permitir realizar interferência na obra durante o processo possibilitando outros resultados.

A quinta atividade foi à colagem como desafio para o estudo do texto. Nessa prática mais uma vez foi solicitado que levássemos imagens que referenciam nossa pesquisa e no dia da aula a mesa da professora estava repleta de materiais artísticos para que utilizássemos livremente na composição da obra. Além desses materiais tínhamos que pegar uma bolinha de papel amassada que estava em cima da mesa. Nessas bolinhas tinham textos que deviam ser articulados com a nossa colagem.

A minha produção mais uma vez dialoga com o bordado, pois levei uma imagem retratava um coração feito com linhas vermelhas, nele havia uma tesoura cravada e uma redoma de vidro que o protegia (Fig. 06). Já meu texto trata dos conflitos existentes entre teoria e prática no ensino das artes, da relação professor e aluno e do estado no qual se 


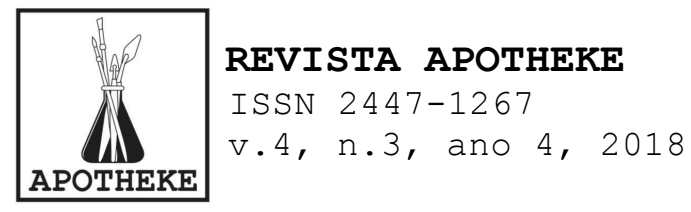

encontra o ensino das artes no momento atual. Então elaborei uma colagem na qual o papel representava o muro de uma casa pichado com vários dizeres, as portas e as janelas estavam lacradas, como se algo ruim tivesse acontecido lá dentro ou precisasse ser contido. E na faixa que lacrava o lugar tinha escrito inspiração.
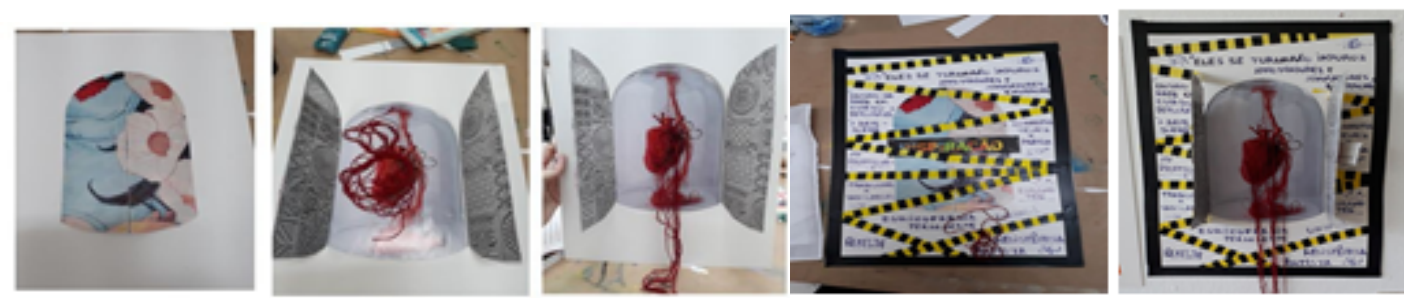

Figura 06 - Atividade realizada na disciplina Sobre ser artista professor. Fonte: Acervo pessoal.

Na verdade o trabalho era uma metáfora de como vejo toda a situação do ensino das artes, da educação bem como da relação da teoria e da prática nas escolas e da relação aluno e professor. De forma geral parece que tudo é proibido e encontra-se sufocado, reprimido. Por isso durante a apresentação do trabalho abri a janela, rompi o lacre da inspiração para que ela pudesse fluir. Ao abrir a janela linhas vermelhas caíram saindo de dentro do coração, agora livres para inspirar. Particularmente, gostei muito de fazer esse trabalho e adorei o resultado.

\section{Seminário}

Por fim a sexta atividade foi à apresentação dos seminários. Neles devíamos escolher um texto de uma lista que havia sido disponibilizada para todos os alunos e montar um seminário que articulasse o texto, com nossas vivências durante o semestre tanto a partir das aulas abertas, como dos minicursos, dos demais textos lidos na disciplina, das 


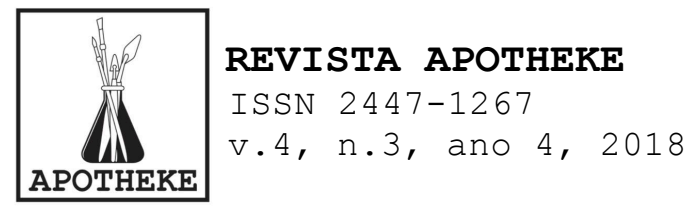

atividades práticas realizadas e do nosso tema de pesquisa. Por fim foi acrescido a tudo isso os OVNI's. Objetos que nos foram entregues dentro de um envelope.

O texto escolhido por mim e pela minha colega Káritha foi "O professor e o mágico são os artistas" de Michel Zózimo da Rocha, que trata das relações estabelecidas pelo autor a respeito do professor, do mágico e do cientista. É um texto bem agradável, que traz exemplos interessantes de artistas que se destacaram por trabalhar a autonomia da arte a partir de ideias inusitadas e levá-las para o cotidiano como foi o caso do "Museu Chapéu" de Robert Filliou, o chamado Galerie Légitime, 1961. Exposição itinerante miniaturizada (Fig. 07). Bem como o trabalho de Piero Manzoni, 1961 com a Base Mágica Escultura Viva, que convertia o status de todos os indivíduos em verdadeiras obras de arte (Fig. 07). E Ben Vautier, com a Caixa Misteriosa - Bô̂te Mystère, que continha os dizeres: "Não abra. Esta caixa perderá todo o seu valor estético se você abrí-la"(Fig.08).

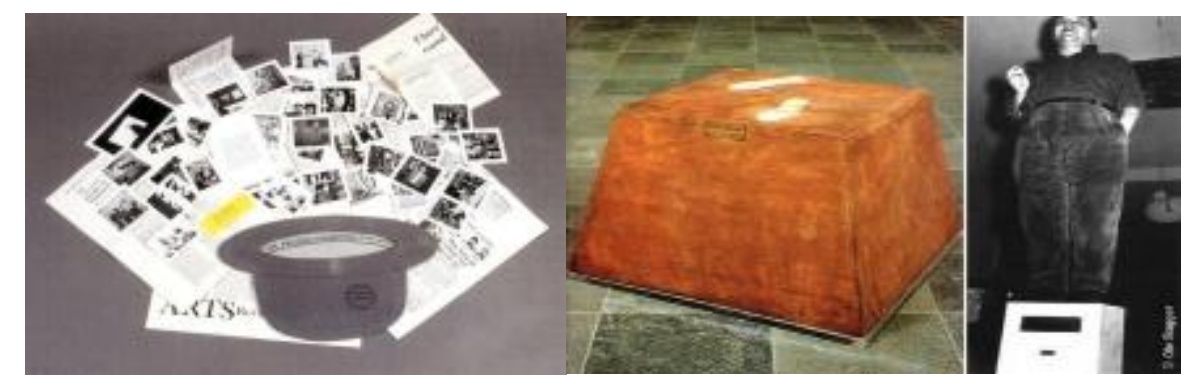

Figura 07 - "Museu Chapéu" de Robert Filliou e Piero Manzoni, 1961 com a Base Mágica - Escultura Viva. Fonte:Imagem capturada em <https://www.wikiart.org/en/robert-filliou/galerie-legitime-1972>; <http://tuttosu.virgilio.it/detail/Indelebili-Tracce-\%C2\%96-Pubblicocome-Opera-doC2\%92Arte, IMBL_13611499_328539.html> 

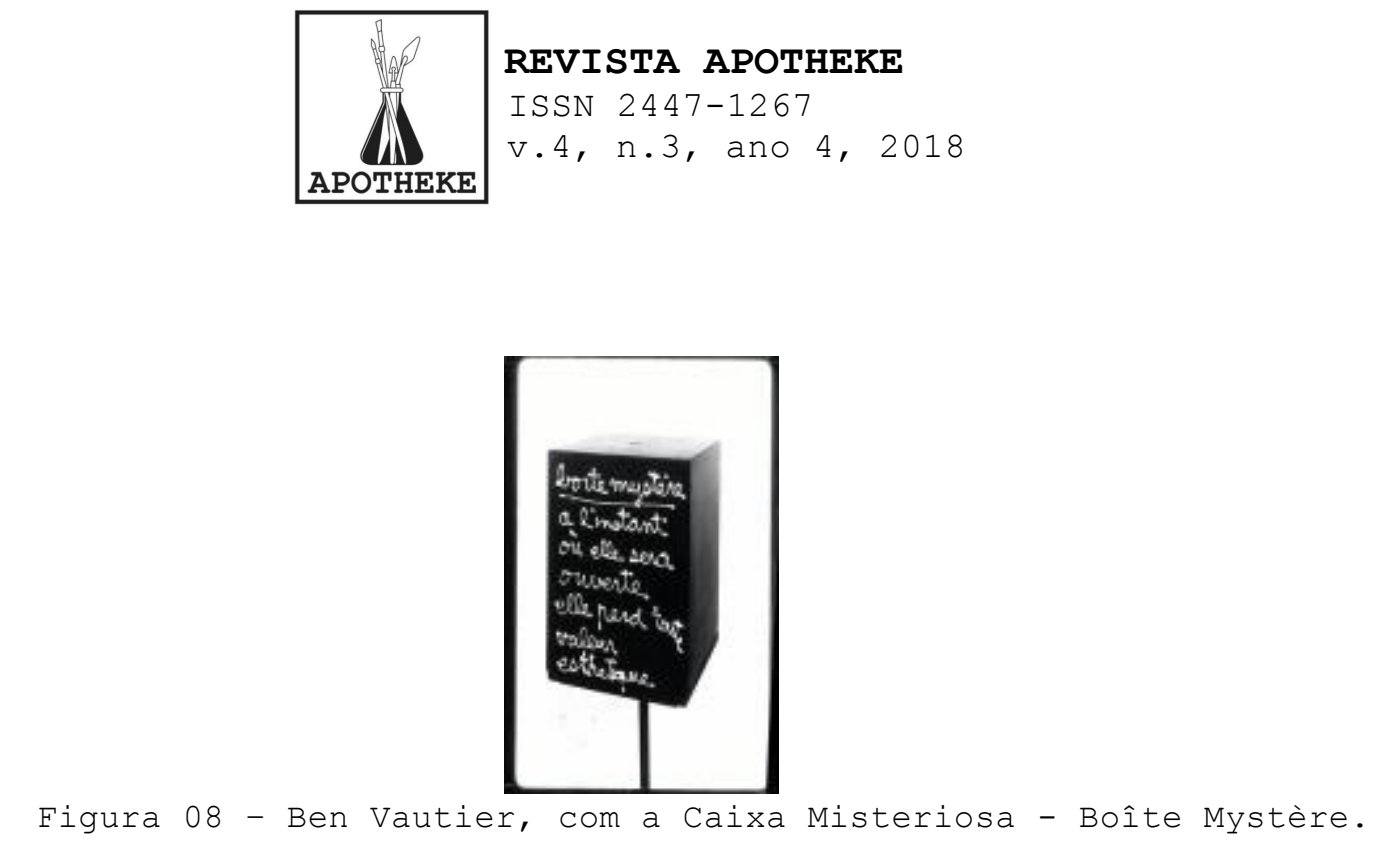

Fonte: Imagem capturada em <http://pantalaskas.e-monsite.com/albumphotos/la-parole-dans-l-oeuvre/boite-mystere.html>

Para tanto fizemos uma apresentação que articulou com o texto e com as falas dos palestrantes da disciplina, bem como com as atividades que havíamos realizado em sala de aula. Citamos diversos autores que articulavam com o tema e por fim construímos um objeto a partir de uma ideia do texto e usando os OVNI'S.

Antes de falar do objeto construído por mim, cabe destacar - conteúdo do envelope, ou seja, o que eram os OVNI'S objetos voadores não identificáveis. Eram seis ao total, uma pedra, um saquinho com areia, um bastão de massa de modelar, uma peça de um quebra cabeça e duas folhas de um livro (Fig.09).

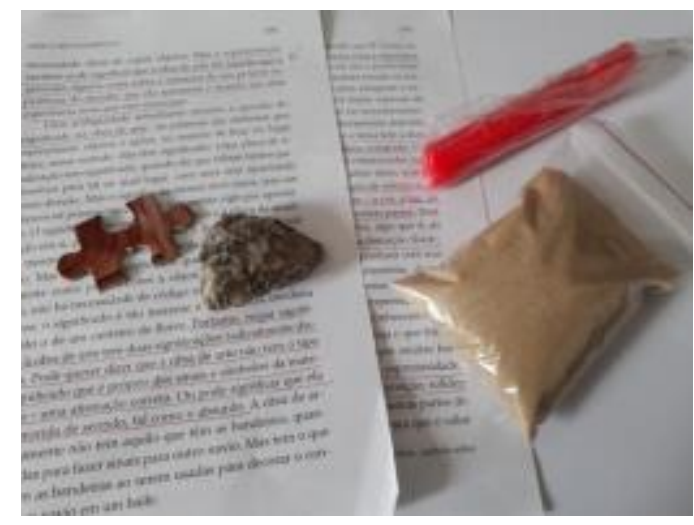

Figura 09 - OVNI'S. Fonte: Acervo pessoal. 


\section{REVISTA APOTHEKE}

ISSN 2447-1267

v.4, n.3, ano 4, 2018

Meu objeto foi construído a partir do entendimento que tive após a leitura das duas folhas que tinham no meu envelope. Elas abordavam a questão do espaço da arte e das suas significações. Então imaginei um lugar que gosto muito, uma praia. Pensei na arte como um barco à deriva sem nunca saber para onde ir e qual o seu lugar de pertencimento, mas sempre a navegar, sempre em movimento afinal, movimento é vida. Depois pensei nos artistas, nos críticos, no público, nos professores e alunos, sempre tentando orientar a arte para algum lugar e me veio à imagem do farol a iluminar e a guiar o barco. Pronto! Estava montado o meu cenário/metáfora.

Então modelei um farol com a massinha de modelar vermelha e firmei-o na pedra depois contornei com areia. No barco à deriva, que representava a arte, fiz sua estrutura com a pecinha do quebra cabeça e com um pedaço de papel construí suas velas. Pintei o mar que separava o barco do farol com aquarela e coloquei tudo dentro de uma caixa preta. Lacrei a caixa e escrevi na sua frente "Não abra. Esta caixa perderá todo o seu valor estético se você abri-la", fazendo referência à obra de Bem Vautier, que constava no texto de zózimo (Fig.10).
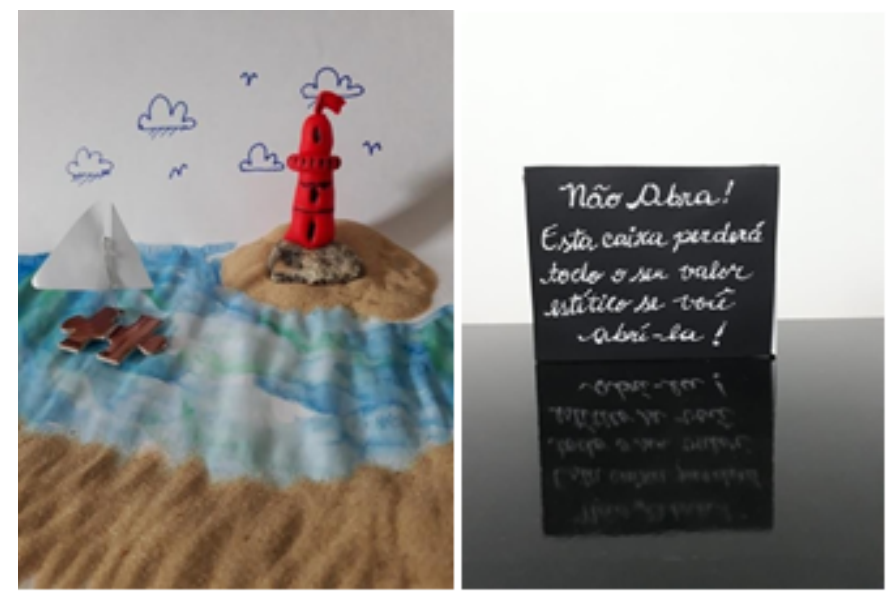

Figura 10 - Objeto criado a partir dos OVNI'S. Fonte: Acervo pessoal. 
E assim finalizamos a apresentação do seminário, tentando articular tudo que havíamos vivenciado durante a disciplina fazendo caber em uma caixinha preta, pois se pensarmos foi a respeito disso que Dewey falou ao mencionar liberdade, experimentação e experiências, ou o prof. José Carlos ao dizer que através da arte conhecemos a nossa verdade, ou como defende John Cage ao afirmar que 0 ensinar e 0 aprender caminham juntos.

\section{Considerações Finais}

Penso que a disciplina sobre ser artista professor representou uma caminhada para cada aluno rumo a sua autodescoberta como artista, como professor, como ser criativo e produtor de objetos, logo um ser pensante e reflexivo. Permitiu através da leitura dos textos o contato com novos autores ou o reencontro com autores até então esquecidos.

Bem como apresentou vozes desconhecidas para nós como o Prof. Dr. Marcus Vinícius, a Dra. Tatiana e o Prof. Dr. José Carlos, assim como a voz de cada colega que se manifestou através de uma pergunta, uma dúvida, uma exposição de ideias, da apresentação de um trabalho ou seminário.

As experiências foram compartilhadas, extrapolando por vezes o universo da arte. Presenciei momentos de pura emoção onde os colegas desabafaram suas angústias e frustrações em relação a suas pesquisas, seu trabalho e suas criações, mas foi muito bom ver ao final todos juntos finalizando mais uma etapa da pós-graduação e de suas vidas.

Como afirma prof. Marcus Vinícius é fundamental que o nosso cotidiano seja constituído por experiências prazerosas, pois é no contexto desse ambiente que se forma a sensibilidade estética, sem a qual não há experiência artística e foi isso que a disciplina proporcionou um ambiente artístico. 


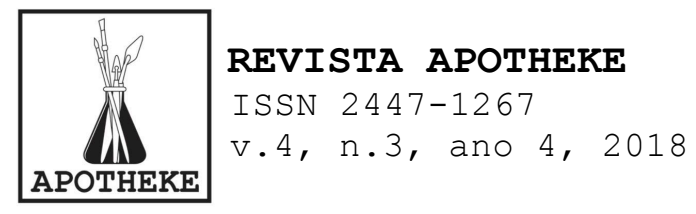

São por momentos como os citados durante todo o texto que acredito no ensino das artes visuais, no entendimento de que a arte é fundamental, pois trás a passagem do nada ao ser, é a união de pólos, é autônoma. Por isso, assim como afirma Heiddegerd, nas palavras do prof. José Carlos, acredito que aquilo que se vê através da arte se vê melhor e que a nossa essência só dá para ser conhecida através da arte.

\section{REFERÊNCIAS}

CUNHA, Marcus Vinicius. John Dewey: uma filosofia para educadores em sala de aula. Petrópolis: Vozes, 1994.

DEWEY, John. Arte como experiência. São Paulo: Editora Martins, Fontes, 2010 .

JESUS, Joaquim A. Luz de. (In)Visibilidades: um estudos sobre o devir do professor-artista no ensino em artes visuais - Tese de Doutoramento em Educação Artística - UPorto - Portugal, 2013.

Heidegger, Martin, A Origem da Obra de Arte, $\mathbf{M}^{a}$. da Conceição Costa (trad.), Edições 70, Lisboa, 1991.

Gadamer, Hans-Georg, Arte y Verdad de la Palabra, J. F. Zúñiga García (trad.) Paidós, Barcelona-Buenos Aires-México, 2012.

\section{Paula Rodrigues}

http://lattes.cnpq.br/5496538818521847

Doutoranda no Programa de Pós-Graduação em Artes Visuais pela Universidade do Estado de Santa Catarina - UDESC. Mestra em Design pela Universidade Anhembi Morumbi de São Paulo - UAM. Especialista em Teorias da Comunicação e da Imagem pela Universidade Federal do Ceará - UFC. Graduada em Design de Moda pela Faculdade Católica do Ceará e graduada em Artes Plásticas pelo Instituto Federal de Educação, Ciência e Tecnologia do Ceará - IFCE. Atua como docente da Universidade do Estado de Santa Catarina no curso de Bacharelado em Moda na área da Linguagem Visual. 